\section{Uneconomic bonding in glasses}

\author{
Bernard de Jong
}

STUdiEs of amorphous materials, those having no form or (by implication) structure, have become increasingly sophisticated over the past ten years. Geologists wishing to understand the crystallization sequence of molten aluminosilicates have resorted to model studies of simple systems. Such a study, on amorphous sodium silicate, is reported by J.F. Stebbins on page 465 of this issue ${ }^{1}$. Stebbins resolves an important argument about the types of bonding in glasses, showing that more types are present than are required stoichiometrically.

New ideas about the structure of amorphous silicates arose in the $1970 \mathrm{~s}$ as a result of experimental evidence for alkali clustering and for the presence of a range of silica species. It had long been recognized that the liquidus curve in alkalisilicate phase diagrams deviates from the ideal shape, most strongly in the lithium-silicate system ${ }^{2}$. Standard thermodynamic theory explained such deviation as being caused by clustering of the lithium atoms. It remained an open question how such clustering came about and if there existed any experimental evidence for it on an atomic scale. A partial answer to this question required characterization of the types of oxygen in a glass. At most three types can occur: bridging oxygens associated with two silicon atoms, Si-O$\mathrm{Si}$; non-bridging oxygens associated with a silicon and alkali atom (R), Si-O-R; and non-bonding oxygens associated with alkalis only, $\mathrm{R}-\mathrm{O}-\mathrm{R}$.

In the first experimental study on the concentration of these three different types of oxygen atoms in silicate glasses, Brückner and co-workers showed that the shape of the oxygen $1 s$ spectral line indicates that non-bonding oxygens are not present in silica-rich alkali-silicate glasses ${ }^{3}$. Hence, clustering of alkalis does not create non-bonding oxygens and by implication involves linkage to a silicon atom. Molecular orbital calculations for the canonical $\mathrm{H}_{6} \mathrm{Si}_{2} \mathrm{O}_{7}$ molecule show that clustering of alkalis in an amorphous silicate is reflected by preferential attachment of the lighter alkalis to silicon tetrahedra that already have an alkali attached to them ${ }^{4}$. These results suggested that, within stoichiometric constraints, four lithium atoms would be attached to a single silica tetrahedron in amorphous lithium silicates, whereas such a configuration would not occur in equimolar amorphous caesium silicates.

The second line of evidence came from Fourier-transform nuclear magnetic resonance (NMR) spectra of aqueous alkali-silicate solutions ${ }^{5.6}$. Spectra of such solutions show the presence of a distribution of different silica species that varies as a function of hydroxyl content, confirming previous potentiometric results ${ }^{7,8}$. Five species were discovered, designated $\mathrm{Q}^{0}-\mathrm{Q}^{4}$, indicating that the central siliconoxygen tetrahedron is surrounded by $0-4$ bridging oxygens (see figure). Moreover, the character of the third-nearestneighbour silicon atom affects the ${ }^{29} \mathrm{Si}$ NMR chemical shift. The number of possible variations of local environment was

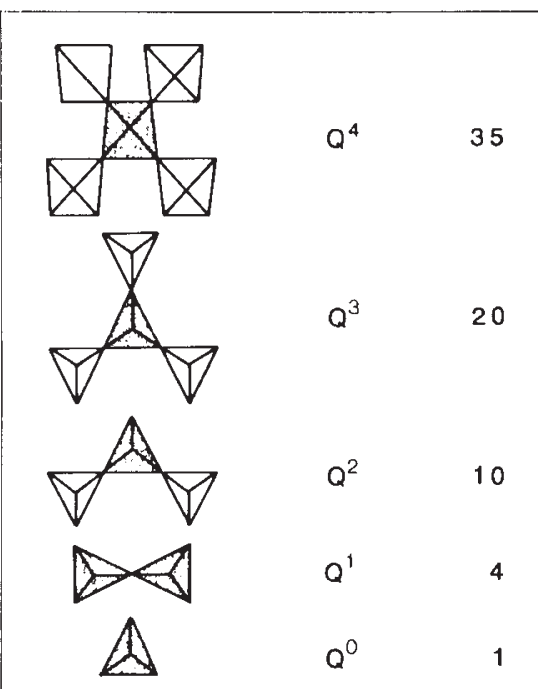

The structure and designation of the silica species, and the possible number of local, up to fourth-nearest neighbour, environments around a silica tetrahedron ${ }^{5}$.

evaluated taking such third-nearestneighbour interactions into account, as shown in the figure.

Our experiments in the early 1980 s to determine the silica species distribution in amorphous alkali silicates ${ }^{4}$ used the variations in line shape of the silicon $\mathrm{K} \beta$ $\mathrm{X}$-ray emission spectrum to determine $\mathrm{Q}^{4} /\left(\mathrm{Q}^{0}+\mathrm{Q}^{1}+\mathrm{Q}^{2}+\mathrm{Q}^{3}\right)\left(\right.$ or $\left.\mathrm{Q}^{4} / \mathrm{Q}^{\mathrm{R}}\right)$ ratios. In addition we found that different alkalis in alkali-silicate glasses give different $\mathrm{Q}^{4} / \mathrm{Q}^{\mathrm{R}}$ ratios. Individual species distributions, however, were still not amenable to experimental verification. It was hoped that ${ }^{29} \mathrm{Si}$ magic-angle-spinning $\mathrm{NMR}^{9}$ would change that, but poor spectral resolution remained a problem. Even in favourable cases, only $\mathrm{Q}^{4} / \mathrm{Q}^{\mathrm{R}}$ ratios could be determined unequivocally ${ }^{10}$. Spectral assignments to different species were tentative because silicon chemical shifts in the glasses do not correspond one-to-one with those in crystalline precipitates. Also the species distributions that were determined using best-fit gaussians did not give the proper stoichiometry in the high-silica glasses. Two schools of thought developed: one maintaining that only one or two species are present and hence suggesting an economy in the distribution ${ }^{10}$; the other that all species were present in varying concentrations which would be tantamount to an uneconomic distribution ${ }^{11,12}$.

The paper by Stebbins in this issue addresses one main question and three secondary ones. The main question is that there is a reasonably quantifiable, uneconomic species distribution, consisting of $\mathrm{Q}^{2}, \mathrm{Q}^{3}$ and $\mathrm{Q}^{4}$, in the composition range considered. This coincides with our conclusion based on NMR results that no single silica species exists in aqueous silicate solutions even in dilute (100 parts per million) solutions ${ }^{13}$. The secondary results are that the NMR lines are not as broad as anticipated, indicating that sodium-silicate glasses are not as aleatoric as expected from the number of possible configurations shown in the figure. Furthermore, Stebbins' results suggest that sodium-silicate glasses tend towards a narrower species distribution than that encountered in lithium-silicate glasses, demonstrating the difference in impact of different alkalis on the structure of alkalisilicate glasses. Finally, his results indicate that radial-distribution analysis samples the character of the average structure in contrast with ${ }^{29} \mathrm{Si}$ magic-angle-spinning NMR, which samples the distributive structure. Taken together, Stebbins' results show that sodium-silicate glasses are weakly random relative to glass systems with a binomial distribution of silica species.

Stebbins' convincing proof for the existence of a silica species distribution and its variation with different alkalis is an important step in unravelling the structure of amorphous alkali silicates. The principal remaining issue in explaining the physical properties of amorphous alkali silicates is how these different species are connected, and also how this connectivity varies as a function of the type of alkali present and what its effect is on the percolation threshold.

1. Stebbins, J.F. Nature 330, 465-467 (1987).

2. Kraceck, F.C. J. phys. Chem. 34, 2645-2665 (1930)

. Brückner, R., Chun, H-U. \& Goretzki, H. Glastech. Ber. 49, 211-213 (1976).

4. de Jong, B.H.W.S., Keefer, K.D., Brown, G.E. \& Taylor, C.M. Geochim cosmochim. Acta 45, 1291-1309 (1981)

5. Engelhardt, G., Zeigan, D., Jancke, H., Hoebbel, D. \& Weiker, W. Z. anorg. allg. Chem. 418, 17-28 (1975).

6. Marsmann, H.C. Z. Naturf. B29, 495-459 (1974)

7. Lagerström, G. Acta chem. Scand. 33, 722-736 (1959)

8. Ingri, N. Acta chem. Scand 13, 758-775, (1959).

9. Lippmaa, E. et al. J. Am. chem. Soc. 102, 4889-4893 (1980).

10. de Jong, B.H.W.S., Schramm, C.M. \& Parziale, V.E J. Am. chem. Soc. 106, 4396-4402 (1984).

11. Grimmer, A.R. et al. Phys. Chem. Glasses 25, 105-109 (1984)

12. Dupree, R., Holland, D., McMillan, P.W.\& Pettifer, R.F J. Non-Cryst. Solids 68, 399-410 (1986).

13. Cary, L.W., de Jong, B.H.W.S. \& Dibble, W.E Geochim cosmochim. Acta 46, 1317-1320 (1982).

Bernard de Jong is in the Department of Applied Physics, Corning Glass Works, Corning, New York 14831, USA. 